\title{
Anne Coudreuse, Le langage du corps souffrant dans quelques cuvres du XVIII siècle
}

\section{Serena Rampazzo}

\section{(2) OpenEdition}

1 Journals

\section{Edizione digitale}

URL: http://journals.openedition.org/studifrancesi/34717

DOI: 10.4000/studifrancesi.34717

ISSN: 2421-5856

\section{Editore}

Rosenberg \& Sellier

\section{Edizione cartacea}

Data di pubblicazione: 1 novembre 2005

Paginazione: 419

ISSN: 0039-2944

\section{Notizia bibliografica digitale}

Serena Rampazzo, «Anne Coudreuse, Le langage du corps souffrant dans quelques œuvres du XVIIIe siècle», Studi Francesi [Online], 146 (XLIX | II) | 2005, online dal 30 novembre 2015, consultato il 18 avril 2021. URL: http://journals.openedition.org/studifrancesi/34717 ; DOI: https://doi.org/10.4000/ studifrancesi.34717

Questo documento è stato generato automaticamente il 18 avril 2021.

\section{(c)}

Studi Francesi è distribuita con Licenza Creative Commons Attribuzione - Non commerciale - Non opere derivate 4.0 Internazionale. 


\title{
Anne Coudreuse, Le langage du corps souffrant dans quelques œuvres du XVIII ${ }^{\mathrm{e}}$ siècle
}

\author{
Serena Rampazzo
}

\section{NOTIZIA}

ANNE COUDREUSE, Le langage du corps souffrant dans quelques ceuvres du XVIII e siècle, in Le corps à fleur de mots. Sous la direction de ELISA GIRARDINI et GENEVIÈVE HENROT, Padova, Unipress, 2004, pp. 43-67.

1 Il saggio, che si inserisce in un volume il cui filo conduttore è il rapporto tra corpo e scrittura nella letteratura francese dal XVI secolo ad oggi analizzato secondo prospettive differenti, conclude la prima sezione, che adotta un'ottica di tipo storico, poetico e retorico, ed è dedicato alla rappresentazione del corpo sofferente in alcuni romanzi e testi teatrali del XVIII secolo. La laicizzazione della società e lo sviluppo dell'anatomia e della medicina determinano la nascita di una nuova semiologia del corpo che, in aperta rottura con la tradizione classica, è basata su tutta una serie di importanti cambiamenti: la rilevanza attribuita alle membra inferiori, in particolar modo alle ginocchia, sedi del pathos e capaci di esprimere diverse emozioni, come emerge ad esempio in La Mère coupable di Beaumarchais e in La Nouvelle Héloïse di Rousseau; la codificazione delle espressioni del volto, la leggibilità del quale entra però in crisi nell'ultimo terzo del secolo; l'importanza primaria attribuita alle sensazioni, che, mettendo in discussione il sistema metafisico e dualistico tradizionale, abbandona il ritratto fisso, statico e stereotipato della retorica classica a favore di una rappresentazione più dinamica e il più delle volte frammentaria, in quanto focalizzata solo su alcune parti del corpo; un nuovo ideale di bellezza, convulsa e deformata dalla sofferenza, che, esaltata ne Les Malheurs de la vertu di Sade, è generata dall'interesse per l'anatomo-patologia; ed infine una nuova percezione del dolore, che affiora ad esempio nella Religieuse di Diderot, il quale, tracciando un vero e proprio quadro clinico dei 
sintomi dell'isteria di Suzanne Simonin, segno della follia e dell'alienazione causatele dalla vita claustrale, sviluppa un discorso morale e medico in difesa del diritto al piacere. Il pathos espresso da questi corpi attraverso convulsioni, svenimenti, tremolii, deliri e altri sintomi simili a quelli dell'isteria, rappresenta secondo Anne Coudreuse «une brève folie organisée pour échapper à la folie réelle vers laquelle risque de dériver la souffrance», un antidoto alla follia che può causare la sofferenza. Si tratterebbe dunque di un tentativo di dominare la follia, regolamentandola e dandole una forma estetica ben precisa. 